\title{
Correction to: Comparison of fibula strut and calcium phosphate cement augmentation of the medial buttress in 2-part proximal humerus fractures reconstruction: a biomechanical study
}

\author{
Dmitry Pokhvashchev $^{1}$ (I) $\cdot$ Riley Knox ${ }^{1} \cdot$ Matthew Herring $^{1} \cdot$ Safa Herfat $^{1} \cdot$ Meir Tibrin Marmor $^{1}$
}

Published online: 18 January 2022

๑) Springer-Verlag France SAS, part of Springer Nature 2022

\section{Correction to: \\ European Journal of Orthopaedic Surgery \& Traumatology \\ https://doi.org/10.1007/s00590-021-03147-1}

The original version of this article unfortunately contained a mistake. The first and last names of the few authors have been switched in the author names, Authors' contribution section and Conflict of interest section.

Author names should be
First name-Matthew, Last name-Herring).

First name-Safa, Last name-Herfat).

First name-Meir, Last name-Tibrin Marmor).

The original article has been corrected.

Publisher's Note Springer Nature remains neutral with regard to jurisdictional claims in published maps and institutional affiliations.

The original article can be found online at https://doi.org/10.1007/ s00590-021-03147-1.

Dmitry Pokhvashchev

Dmitry.Pokhvashchev@ucsf.edu

Meir Tibrin Marmor

Meir.Marmor@ucsf.edu

1 University of California, San Francisco, USA 